[PREPRINT]

\title{
Renewable energy in copper production: a review on systems design and methodological approaches
}

\author{
Simón Moreno-Leivaa, ${ }^{\mathrm{a},}$, Jannik Haas ${ }^{\mathrm{a}}$, Tobias Junne ${ }^{\mathrm{c}}$, Felipe Valencia ${ }^{\mathrm{d}}$, Hélène Godin ${ }^{\mathrm{b}}$, Willy \\ Krachte,f $^{\mathrm{e}}$, Wolfgang Nowak ${ }^{\mathrm{a}}$, Ludger Eltrop ${ }^{\mathrm{b}}$ \\ *Corresponding author: smorenoleiva@gmail.com \\ a) Department of Stochastic Simulation and Safety Research for Hydrosystems (IWS/SC SimTech), University of Stuttgart, \\ Pfaffenwaldring 5a, 70569 Stuttgart, Germany \\ b) Institute of Energy Economics and Rational Energy Use (IER), University of Stuttgart, Heßbrühlstraße 49A, 70565 \\ Stuttgart, Germany \\ c) Department of Energy Systems Analysis, Institute of Engineering Thermodynamics, German Aerospace Center (DLR), \\ Pfaffenwaldring 38-40, 70569 Stuttgart, Germany \\ d) Energy Center, Department of Electrical Engineering, University of Chile, Tupper 2007, Santiago, Chile \\ e) Department of Mining Engineering, University of Chile, Beauchef 850, Santiago, Chile \\ f) Advanced Mining Technology Center (AMTC), University of Chile, Tupper 2007, Santiago, Chile
}

\begin{abstract}
Renewable energy systems are now accepted to be mandatory for climate change mitigation. These systems require a higher material supply than conventional ones. Particularly, they require more copper. The production of this metal, however, is intensive in energy consumption and emissions. Therefore, renewable energy systems must be used to improve the environmental performance of copper production.

We cover the current state of research and develop recommendations for the design of renewable energy systems for copper production. To complement our analysis, we also consider studies from other industries and regional energy systems.

We provide six recommendations for future modeling: (a) current energy demand models for copper production are overly simplistic and need to be enhanced for planning with high levels of renewable technologies; (b) multi-vector systems (electricity, heat, and fuels) need to be explicitly modeled to capture the readily available flexibility of the system; (c) copper production is done in arid regions, where water supply is energy-intensive, then, water management should be integrated in the overall design of the energy system; (d) there is operational flexibility in existing copper plants, which needs to be better understood and assessed; (e) the design of future copper mines should adapt to the dynamics of available renewable energy sources; and (f) life cycle impacts of the components of the system need to be explicitly minimized in the optimization models.

Researchers and decision-makers from the copper and energy sector will benefit from this comprehensive review and these recommendations. We hope it will accelerate the deployment of renewables, particularly in the copper industry.
\end{abstract}

Keywords: Renewables in mining; copper production; renewable energy systems; energy systems design; optimization 


\section{Introduction}

The use of renewable energy (RE) in the copper industry is not new. For example, there are power purchase agreements (energy contracts) for renewable electricity supply (e.g. wind power for the Los Pelambres copper mine in Chile (Choi and Song, 2017)). Solar heat plants are also in use, such as the Pampa Elvira Solar flat plate collector plant which supplies low-temperature heat for a Codelco's operation (Díaz-Ferrán et al., 2015). In spite of proven technical feasibility, the overall penetration of renewables in the copper sector remains low. For instance, the energy requirements for transport and heat are usually covered by fossil fuels and electricity generation is mostly based on conventional technologies. For example, in Chile (the world's leading copper producer), half of the energy consumed in the sector comes directly from fossil fuels (COCHILCO, 2018). The other half is electricity, half of which is produced with fossil fuels (CNE, 2019).

As the costs of renewable energy technologies continue to decrease, they gradually outperform conventional technologies. For example, Lazard (2018) reports that the lower end of the levelized costs of electricity of photovoltaics (PV) and wind are down to 40 and $30 \mathrm{USD} / \mathrm{MWh}$, while coal power sits at $60 \mathrm{USD} / \mathrm{MWh}$. Moreover, the latest tenders reveal bid prices even lower than 20 USD/MWh for PV (Willuhn, 2019). In a comprehensive review, Brown et al. (2018) underline that fully RE-based systems are not only technically feasible but also economically viable.

The relationship between copper and renewables is complementary. On the one hand, copper is needed for renewable energy systems. On the other, renewables can improve the environmental performance of the copper industry. For this reason, it is relevant and timely to look at the link between copper and RE, as well as to elucidate the road to their optimal integration. Sections 1.1 and 1.2 offer further insights into this relationship.

\subsection{More copper will be needed for future energy systems}

Fully renewable energy systems are required to mitigate climate change (Ram et al., 2019; Teske, 2019; IEA, 2018) and the copper industry would play a role in the transition to such systems. As RE technologies require more copper than conventional ones (as copper use per unit of energy produced) (Kleijn et al., 2011), transitioning towards highly renewable energy systems is a driver for copper demand (Schipper et al., 2018). Figure 1 shows the copper demand for selected technologies. More copper is required to produce electricity from PV and wind. In addition to RE generation technologies, transmission reinforcement (required to balance variable generation) and the deployment of electric mobility would also drive copper demand. Hertwich et al. (2015) dismiss the possibility of a resource constraint on copper, estimating the use of copper for building 2050's world energy system at twice the current annual production. Nevertheless, with the depletion of copper deposits, the specific energy required for extraction increases. As a consequence, the energy return on investment of, for example, a wind turbine in the year 2050 would decrease by 15\% as compared to 2012 (Harmsen et al., 2013). Without a transition to renewable energy sources, greenhouse gas emissions will increase too. 


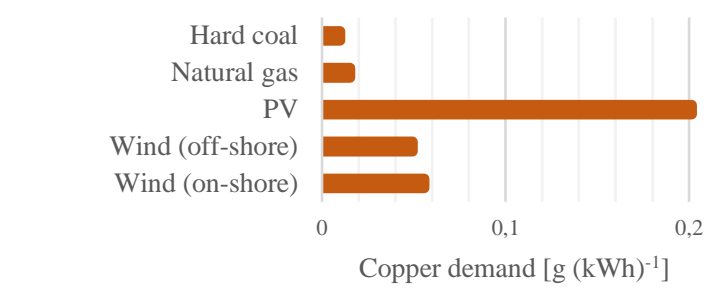

Figure 1: Copper demand for different generation technologies ${ }^{1}$

\subsection{Renewable energy systems can improve the footprint of copper}

Copper has an ecological footprint that is relevant to the technologies that will form the future energy system. To assess the impacts, Life Cycle Assessment (LCA) methods are usually employed. In LCA, all emissions at every stage of the life cycle of a product or process (including energy and materials supplies) and the resulting impacts on the environment are tallied. This allows for identification of the main impacts, relevant stages, and potential trade-offs when implementing changes. For example, Martínez et al. (2009) showed that copper is a relevant source of impact in wind turbine nacelle construction, where it is used in the generator and transformer. Nacelles, in turn, account for around $30 \%$ of the terrestrial ecotoxicity, petrochemical oxidation, and acidification along with over $40 \%$ of human toxicity associated with the life cycle impacts of wind turbines. In a review of LCA studies on different types of electric cars, Nordelöf et al. (2014) argue that copper supply is an important cause of human toxicity potential. The authors point out that reducing the use of coal in the energy supply of mining would reduce the impact of battery electric vehicles. Alvarado et al. (2002) highlight that, in copper production, the main energy-related impact is the emission of greenhouse gases. Looking at ore grade decline, Castro-Molinare et al. (2014) argue that solar electricity would be the most effective (on-grid) alternative (as compared to wind and natural gas) to compensate for the corresponding increased Global Warming Potential (GWP). In a previous study, we estimated that, by replacing the total electricity demand of copper with solar power, GWP can be reduced by at least $60 \%$ and $75 \%$ for pyro- and hydrometallurgical copper production in Chile (Moreno-Leiva et al., 2017). Other forms of energy would need to be addressed to achieve further reductions.

Finally, the water consumption of copper production can be a major environmental burden, especially in countries that concentrate major copper reserves and where water is scarce (Northey et al., 2017). This means that the mines either compete with other local users for a (very) scarce resource or use seawater (crude or desalinated). The last option translates to an energy supply issue (Ihle and Kracht, 2018), which could be tackled with RE.

The use of renewables can thus be a means to lower the energy-related environmental footprint of copper production processes.

\subsection{The impact of copper comes not only from energy}

Copper production has other environmental impacts that are not related to energy. Although these issues are outside the scope of this study, they are summarized here for the sake of completeness. This should avoid giving the impression that RE technologies could solve all environmental problems in copper production.

\footnotetext{
${ }^{1}$ As reported in the Ecoinvent database version 3 (Wernet et al., 2016) and retrieved through Gabi LCA software. The reference capacities of PV and wind technologies are 0.6 MWp and 1-3 MW. Germany is the reference for the inventories.
} 
Several studies have used LCA to analyze the overall impacts of copper production (Castro-Molinare et al., 2014; Memary et al., 2012; Norgate et al., 2007). Non-energy-related environmental issues are: depletion of the metal, emission of heavy metals and sulfur dioxide to the air at smelters, emission of heavy metals and phosphorous to freshwater, and the land use of tailings storage facilities. Tailings management is an old concern that persists. Castilla and Nealler (1978) analyze the effects of copper mine tailings discharges in the coastal ecosystems of Chañaral in Northern Chile. They dived in an active landfill and found a reduction in light transmittance while simultaneously increasing the mortality of marine species compared to an unpolluted nearby site. Recently, Beylot and Villeneuve (2017) conducted an LCA to measure the environmental impact of tailings from copper production. They compared the impact of this part of the process to those of the rest of the operations. They concluded that when analyzing longer periods (tens of thousands of years) toxicity-related impacts arising from tailings management are higher than those of the stages in the main value chain of copper production. Moreover, risk of landslides exists when deploying tailings dams. These studies highlight that GWP is only one among many indicators needed to describe the environmental impact of copper production.

\subsection{Research questions and contribution}

The design of renewable energy systems for copper production is incipient and its systematic analysis can enhance the results in the field. The scientific literature is diverse and ranges from the evaluation of specific technologies to a few comprehensive system analyses. This study provides a comprehensive overview of the state of research on renewable energy systems for copper production and a number of recommendations for improving the design of these systems. Researchers and decision-makers in the energy sector and copper industry will benefit from this systematic review, which includes lessons learned from other fields where renewable energy systems are being deployed. Our recommendations serve as a guide for the design of the energy supply of existing and future copper production processes. This will, in turn, improve the environmental footprint of renewable technologies that require copper for their construction.

\section{Methods and structure}

This review is based on scientific literature published in peer-reviewed scientific journals, complemented with technical reports and official statistics when required.

The analysis is divided into the steps shown in Figure 2. Section 3.1 clarifies how copper is produced, the amount and type of energy required, how this demand is currently supplied and which factors influence energy consumption. Section 3.2 describes the current state of research on RE systems for copper production supplemented by a classification framework for the methods used in the studies. For a more comprehensive analysis, we consider studies that explicitly analyze the use of RE in copper production and studies that use copper production as a case study. Section 3.3 refers to the literature on renewable energy systems for other applications and sectors, aiming at finding lessons for copper production. Finally, in section 4, we present our recommendations for future research in the field. 


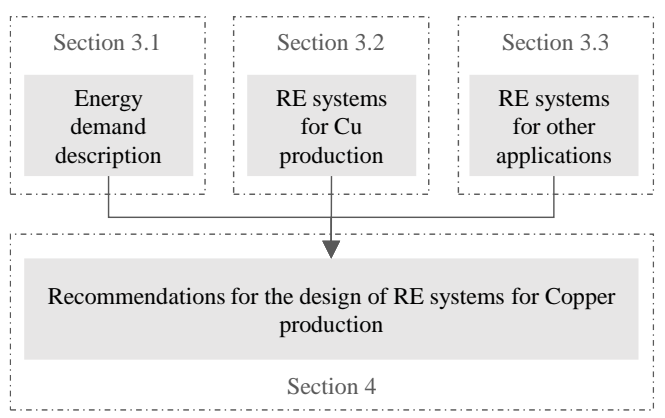

Figure 2: Structure of the analysis.

\section{Design of renewable energy systems for copper production}

\subsection{Energy demand in copper production}

To obtain the 24 million tons of refined copper produced worldwide (International Copper Study Group (ICSG), 2018), there are two main processing routes (see Figure 3): pyro- and hydrometallurgy. These account for $67 \%$ and $16 \%$ of world production. The remaining $17 \%$ corresponds to secondary recycled production (International Copper Study Group (ICSG), 2015), which requires 85\% less energy (International Copper Association - Copper Alliance, 2014). In the following, we briefly describe the first two -more energy-intensive- processes with a focus on energy consumption.

The description of the processes relies mostly on Schlesinger et al. (2011) and the figures on data from a comprehensive annual industry survey conducted by the Chilean Copper Commission (Cochilco, 2018). Figure 4 shows energy consumption in copper production as reported in that survey. Because of greater copper demand and lower quality mineral resources, the total energy required to supply the copper that humanity consumes is expected to increase in the future. Elshkaki et al. (2016) project the energy demand for copper production to grow from around 150 and 100 to 200 and 160 GJ per ton of copper in 2050, for hydro- and pyro-metallurgical processes. The authors highlight that this would equal an impressive $2.4 \%$ of global annual energy demand.

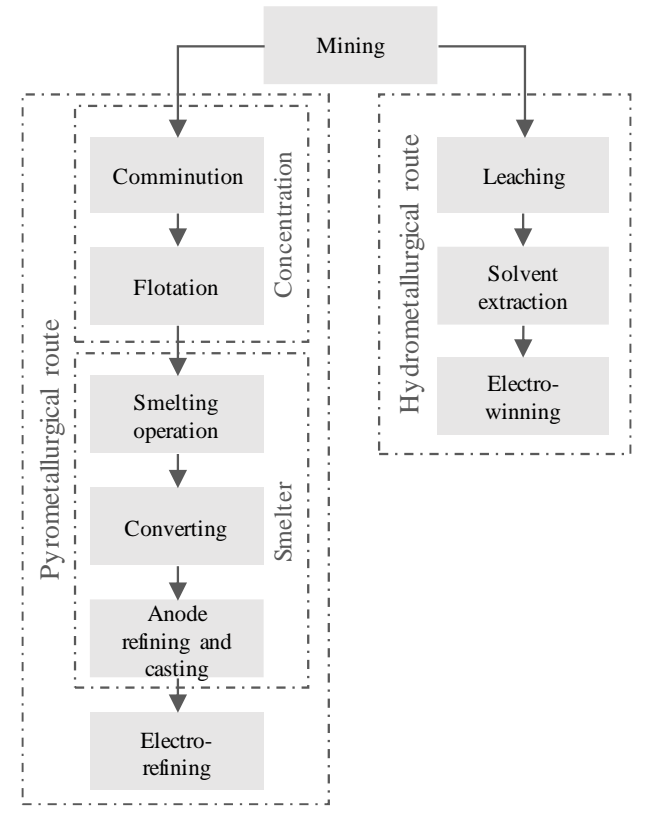

Figure 3: Simplified overview of copper production processes. Based on Schlesinger et al. (2011). 
Both processing routes (hydro- and pyrometallurgy) begin by mining the mineral from the ground. Usually, ores with a lower (around $0.5 \%$ ) grade are mined in open-pit operations, while deposits with higher ore grades (around 1-2\%) are accessed by underground mining. Open-pit mines dominate copper production (Schlesinger et al., 2011). The blasted rock is typically loaded and hauled by large trucks that run onboard diesel generators to power the electric motors that move the vehicle. One example is the Komatsu 930E truck, which is widely used in industry and whose engine has a gross power of 2.6 MW (Komatsu, 2009).

After transport, pyrometallurgical processes are usually used if sulfur and iron are present in the ore. For copper oxide ores, hydrometallurgical methods are used (Schlesinger et al., 2011). Both processing routes are described in the next two sub-sections.

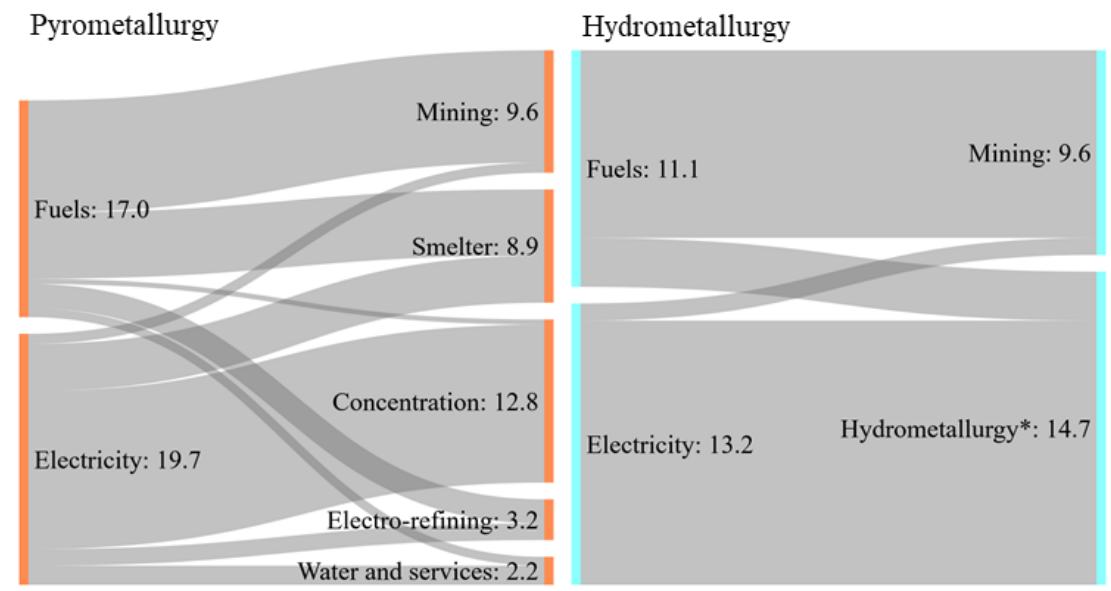

Figure 4: Energy flows in copper production in GJ per ton of copper. Left: Pyrometallurgical copper production. Right: Hydrometallurgical copper production. *Aggregates leaching, solvent extraction, and electro-winning. 2017 averages for the Chilean industry (Data from COCHILCO (2018). Mining is represented with the weighted average of open-pit and underground operations, and no distinction is made between (first-stage) mining for hydro- and pyro-metallurgy.

\subsubsection{The energy demand of pyrometallurgical methods}

Pyrometallurgical copper production starts with fine milling (comminution) of the mineral. Standard equipment includes semi-autogenous mills, ball mills, and cyclonic separators. The milled mineral is then concentrated to around $30 \%$ of copper content in the froth flotation process. In this operation, the milled mineral is transferred into bubbled water tanks that collect copper-rich particles in the foam formed at the surface. This operation is called froth flotation and its main product is copper concentrate. This stage is intensive in the use of electricity (for the operation of the mills) and water (which may result in further electricity demand for water transport and/or desalination).

High-temperature processes are used to recover the copper from the concentrate by means of density differences. The concentrate is first smelted in the smelting operation $\left(1,250^{\circ} \mathrm{C}\right)$ to produce copper matte (molten phase rich in copper) and slag (oxidized impurities). This operation uses fuels to achieve the required temperature. The matte is then oxidized to $99 \%$ pure copper in the transformation process $\left(1,200^{\circ} \mathrm{C}\right)$ by injecting oxygen-enriched air. The converting operation is auto-thermal, meaning that the chemical reactions provide enough heat to maintain the required operating temperature. Electricity is required for the oxygen supply.

Electro-refining follows, refining the copper anodes cast in a previous stage (99\% pure) through dissolution in an aqueous electrochemical reaction, where the copper ions plate on a $99.99 \%$ pure 
copper cathode. Electricity is required to drive the reaction and heat is needed to maintain the operating temperature of $60-65^{\circ} \mathrm{C}$ (Chen and Dutrizac, 1990).

\subsubsection{The energy demand of hydrometallurgical methods}

The hydrometallurgical processing does not require milling the rocks down to sizes as fine as in the pyrometallurgical route. Instead, the crushed ore is disposed in heaps that are continuously irrigated with an aqueous solution of sulfuric acid, leaching the copper from the rock to the solution.

This solution is concentrated in the solvent extraction operation, where copper is transferred from the aqueous solution to an organic phase and then back to a more concentrated aqueous solution. Up to this point, energy is required for transporting solutions and minerals, and for comminution.

Copper is recovered from the concentrated solution through electro-winning. In this process, copper ions are plated on a $99.99 \%$ pure cathode. This process operates at $45-50^{\circ} \mathrm{C}$. Electricity is required to drive this electrochemical reaction and heat is needed to maintain the temperature.

\subsubsection{Factors that determine the energy demand for copper production}

The main factors that determine the energy consumption in copper production are (1) the process route (pyro- or hydro-metallurgy); (2) ore grade; (3) mineral hardness and liberation size; (4) mine age and type (surface or underground); (5) location of the mine and access to water; and (6) process design and equipment selection. These factors are addressed in the following:

(1) Mineral processing by the pyrometallurgical route (for sulfide ores) or hydrometallurgical route (for oxide ores) involves different operations and equipment, and results in different energy requirements, as explained in the previous section.

(2) The unit energy demand (energy per mass of copper produced) increases with lower ore grades (Norgate and Jahanshahi, 2010). There has been a downward trend in copper ore over the last decade so that more mineral needs to be processed to extract the same amount of metal. For example, in Chile, the average concentration plant copper grade was $1.0 \%$ in 2008, while in 2017 it was $0.8 \%$ (Cochilco, 2017a). In the same period, the energy demand for concentration increased by around $50 \%$ (Cochilco, 2018).

(3) Grinding is the most energy-intensive process in mineral processing (Wei and Craig, 2009). Rock hardness and liberation size are especially relevant in comminution processes since harder rocks require more energy to be milled to the required liberation size (the particle size at which the metal is exposed enough so that it can be recovered in the concentrate). Both rock hardness and liberation size usually vary spatially in the mine. This could be seen as providing demand-side flexibility when considering the integration of solar energy, as shown in Pamparana et al. (2019a, 2019b, 2017a). This would require miners to be open to modifying both the design and operation of the concentrator. The latter, in turn, could affect operational paradigms such as maximizing the throughput being the only operational goal.

(4) Energy consumption also varies between surface and underground mining. For instance, in Chile, the average energy consumption was 10.2 and $4.3 \mathrm{GJ} / \mathrm{t}$ of copper produced at open-pit and underground mines in 2017 (Cochilco, 2018). While open-pit mining uses almost exclusively fossil fuels, half of the energy for underground mining is electric. As mines age, trucks must cover longer distances in the pit, which increases their energy demand (Cochilco, 2017b). The cost of further deepening the mine will rise until it is no longer economically viable to continue open-pit mining. Then, the operation has to transition to underground mining, as it is happening with Chuquicamata and Grasbersg (Fiscor, 2010). 
(5) Depending on the mine location, access to water can be an issue. As pointed out by Ihle and Kracht (2018), the issue of water supply in the use of seawater becomes an energy supply problem, as water has to be pumped and desalinated from the coast. For the Chilean mining industry, it is estimated that the electricity demand for seawater desalination and transport will increase a fourfold over the next decade (Brantes and Cantallopts, 2018). The composition of the minerals, which in turn depends on the location of the mine, can exacerbate the water problem. For example, when the ore has relevant amounts of molybdenum, the use of non-desalinated seawater in the flotation process is discouraged as it undermines its recovery (Ramos et al., 2013). This would add desalination costs (to the seawater transport costs). The location also plays a role as it determines transport distances. Altitude, in particular, affects the head for water pumping systems and the efficiency of combustion processes.

(6) But not every factor is exogenous. Process design and equipment selection determine the quantity and form of energy demand. For example, at the smelter, the choice of equipment determines how much energy is needed overall and how the proportions of fuel and electricity are distributed. For instance, if flash smelting, flash converting, and slag flotation are used, 3.5 GJ and 1.5 GJ of electricity and fuels per ton of copper would be required. If Noranda smelting, Pierce-Smith converters, and slag flotation are used, 4.4 GJ and 4.1 GJ of electricity and fuels per ton of copper would be required (Coursol et al., 2015).

To summarize, the energy demand for copper production is distributed between different operations, and the quantity, form, and dynamics depend on multiple factors, both endo- and exogenous to the process design. Therefore, representing it as an aggregated consumption or neglecting its thorough characterization would considerably limit the design and analysis of renewable energy systems.

\subsection{Studies on designing renewable energy systems for copper production}

In the studies on renewable energy systems for copper production, the approaches vary widely. Aiming for a well-structured analysis, we first define a classification for these different methodological approaches and then provide a review of the literature.

\subsubsection{Classification of models}

Three defining aspects were identified among the approaches to energy system design: 1) the treatment of demand, 2) the consideration of energy vectors or forms of energy, and 3) the operational resolution of the copper processes. These aspects will be described in the following. We selected them as they determine the freedom that the corresponding decision making (optimization problems) would have.

(1) The energy demand of production processes can either be treated as exogenous to the model, meaning that it is an input parameter that must be satisfied and cannot be modified (Figure 5-a) or as endogenous, meaning that the modification of the demand is allowed (Figure 5-b). 


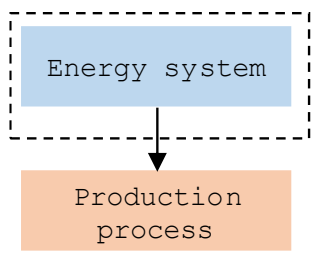

(a)

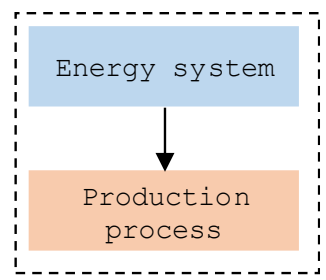

(b)

Figure 5: Methodological classification for energy system design models depending on how the energy demand of the productive processes is treated. The dashed lines represent the components of the system where the model can make decisions. (a) Demand is exogenous (b) Demand is endogenous.

(2) Energy can be considered in three ways: as a single-vector (e.g. only electricity) (Figure 6-a); as non-exchangeable multi-vectors, i.e. consider more than one form of energy without allowing for transformations between them (Figure 6-b); or exchangeable multi-vector, i.e. consider more than one vector and allow for transformations between them (Figure 6-c). The latter gives the most degrees flexibility in the design.

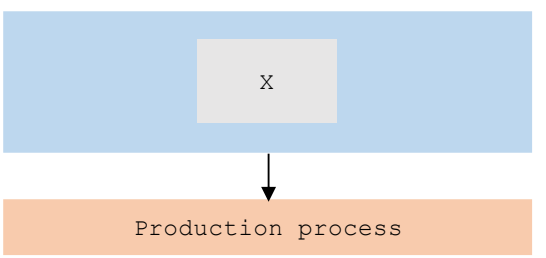

(a)

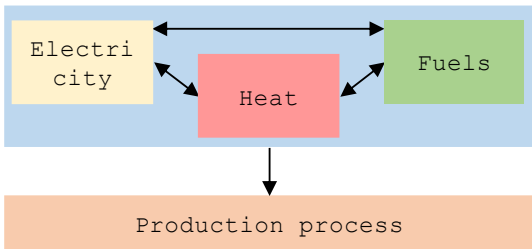

(c)

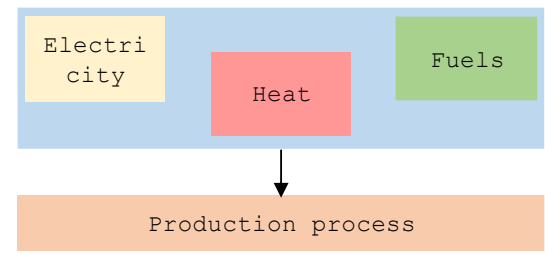

(b)

Figure 6: Methodological classification for energy system design models according to energy vectors. (a) Single-vector (b) Nonexchangeable multi-vector (c) Exchangeable multi-vector

(3) The aggregation and the scope of the description of the energy demand of the production processes vary. We observed three options. First, the demand for the entire process is considered as one aggregated node (full-process aggregated demand, Figure 7-a). Second, a single operation within a production chain is considered while the rest of the operations are neglected (single-operation, Figure 7-b). Third, the entire process with an operation-sharp resolution is considered (full-process, singleoperation resolution) (Figure 7-c).

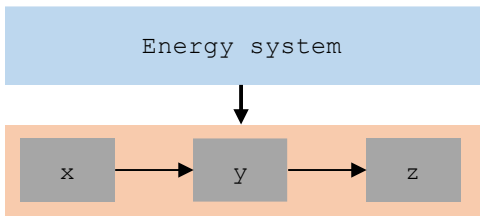

(a)

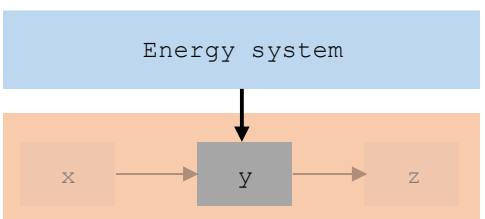

(b)

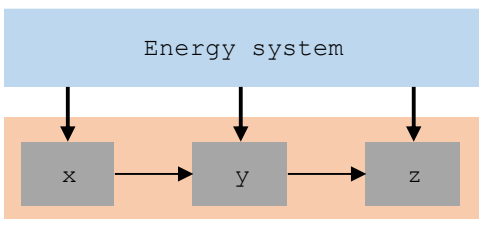

(c)

Figure 7: Methodological classification for energy system design models according to energy demand representation.

(a) full-process aggregated demand, (b) single-operation, (c) full-process, single-operation resolution. 


\subsubsection{Relevant studies}

Eleven studies on the design of renewable systems for copper processes are considered. An overview of these, based on the aforementioned classification, is presented in Table 1. The discussion is divided into two parts. First, studies are reviewed and discussed that consider demand as an exogenous parameter that cannot be changed (studies 1-7). Later, the analysis is performed for the studies that take into account changes in the energy demand of the processes (studies 8-11).

\begin{tabular}{|c|c|c|c|c|c|c|c|c|}
\hline & \multirow[b]{2}{*}{ Study } & \multicolumn{2}{|c|}{$\begin{array}{l}\text { Treatment } \\
\text { of demand }\end{array}$} & \multicolumn{3}{|c|}{$\begin{array}{l}\text { Energy } \\
\text { vectors }\end{array}$} & \multicolumn{2}{|c|}{$\begin{array}{l}\text { Representation of } \\
\text { demand }\end{array}$} \\
\hline & & (1a) & (1b) & $(2 a)$ & $(2 b)$ & $(2 \mathrm{c})$ & (3a) & (3b) \\
\hline (1) & (Castillo et al., 2015) & $\mathrm{x}$ & & $\mathrm{x}$ & & & & $\mathrm{x}$ \\
\hline (2) & (Amusat et al., 2015) & $\mathrm{x}$ & & & & $\mathrm{x}$ & $\mathrm{x}$ & \\
\hline (3) & (Amusat et al., 2016) & $\mathrm{x}$ & & & & $\mathrm{x}$ & $\mathrm{x}$ & \\
\hline (4) & (Amusat et al., 2017) & $\mathrm{x}$ & & & & $\mathrm{x}$ & $\mathrm{x}$ & \\
\hline (5) & (Servert et al., 2015) & $\mathrm{x}$ & & $\mathrm{x}$ & & & $\mathrm{x}$ & \\
\hline (6) & (Vyhmeister et al., 2017) & $\mathrm{x}$ & & $\mathrm{x}$ & & & $\mathrm{x}$ & \\
\hline (7) & (Barrientos et al., 2018) & $\mathrm{x}$ & & $\mathrm{x}$ & & & $\mathrm{x}$ & \\
\hline$(8)$ & (Pamparana et al., 2017) & & $\mathrm{x}$ & $\mathrm{x}$ & & & & $\mathrm{x}$ \\
\hline (9) & (Pamparana et al., 2019a) & & $\mathrm{x}$ & $\mathrm{x}$ & & & & $\mathrm{x}$ \\
\hline (10) & (Cruz-Robles et al., 2018) & & $\mathrm{x}$ & $\mathrm{x}$ & & & & $\mathrm{x}$ \\
\hline (11) & (Díaz-Ferrán et al., 2018) & & $\mathrm{x}$ & & $\mathrm{x}$ & & & $\mathrm{x}$ \\
\hline
\end{tabular}

Table 1: Summary of approaches of studies on renewable energy use in copper production, following the above-explained framework. (1a) Demand-exogenous treatment;(1b) Demand-endogenous treatment; (2a) Single vector;(2b) Non-exchangeable multi-vector;(2c) Exchangeable multi-vector;(3a) full-process aggregated demand;(3b) single-operation;(3c) full-process with single operation resolution.

Seven studies with demand-exogenous approaches are identified. (1) Castillo et al. (2015) present a single-vector, and single-operation energy system design. It is a novel design that supplies a copper electro-refining plant directly with direct current from a PV plant. Since PV technology generates direct current and electro-refining requires electricity in this form, the losses and capital costs of conversion can be avoided. In this case, distributed energy generation avoids not only transmission losses but also those of (electricity) conversion processes. This study shows by way of example the relevance of understanding the end-use of energy in production processes so that the full potential of RE can be exploited.

Next, a series of papers from Amusat's group is introduced. They deal with the design of an interchangeable, multi-vector energy system for copper production, using a full-process aggregation of the energy demand. (2) Amusat et al. (2015) present a method for the minimum capital cost design of RE systems for continuous processes and apply it to a case study of copper production in Chile. They consider two RE generation technologies (PV and concentrated solar heat) and three energy storage technologies (molten salts, pumped hydro, and compressed air) in a set of performance models. The RE system supplies both electricity and heat (as a constant share of electricity), but it does not consider fuels demand (e.g. for trucks). The optimal solution defines hourly time profiles for energy generation, storage, and supply, as well as the sizes for the components. (3) Amusat et al. (2016) extend the method to consider the uncertainty of RE generation profiles in the design of the off-grid RE system. They also add a synthetic case study in Canada. The authors propose modified versions of standard energy systems reliability indexes (expected energy not supplied and energy 
index of reliability) to develop a probability-based model that minimizes costs and unsupplied energy. (4) In Amusat et al. (2017), the authors further extended the method to integrate the optimization of capital costs and system reliability into one multi-objective optimization problem. They solve this problem with an evolutionary algorithm and produce the corresponding Pareto fronts.

(5) Servert et al. (2015) analyze the economic feasibility of providing electricity for mining operations with a CSP plant using a probabilistic model for the energy price. The approach of this study is single-vector and full-process with aggregated demand. They assessed the feasibility of the plant considering standard financial contracts (power purchase agreements) within the industry. Furthermore, they propose economic incentives to improve the competitiveness of CSP. Current market prices are lower than those considered by the authors. In spite of that, the potential for technology learning and the effect of sector coupling should still be considered when assessing the integration of CSP technologies.

(6) Vyhmeister et al. (2017) address the cost-optimal design of a renewable electricity supply system based on photovoltaics and a novel floating wind-power technology. They design the system to supply $10 \%$ of the electricity demand of the mining industry in Antofagasta, Chile. The approach is single-vector and full-process aggregated. Despite the authors argument that the electricity costs of the proposed system (250-270 USD (MWh) $)^{-1}$ ) are only slightly higher than the average prices in the region, this alternative is more than double the average costs of current contracts of large clients (80 USD (MWh) ${ }^{-1}$ (Consejo Minero, 2016)). Such high costs, however, can be explained by conservative cost assumptions and the use of immature technologies in their study. This fact, however, should not discourage the implementation of mature renewable energy systems, which are proven to be technoeconomically viable with their cost decreasing every year (Brown et al., 2018) and already outperforming conventional technologies (as explained in section 1). Moreover, since a $100 \%$ renewable electricity supply is feasible, we see no reason to limit the share of renewables in future systems.

(7) In the last study with an exogenous-demand approach, Barrientos et al., (2018) present an energy management system (EMS). An EMS is a control system that coordinates the operation of an energy system under a certain optimality criterion. In this case, the EMS aims at promoting self-consumption of distributed (local) renewable energy in industrial processes. They apply the method to a windpower system for a copper production process. In this study, the goal was to minimize costs and the energy exports under the assumption that these would not be paid by the national grid operator. We classify this work as single-vector and full-process aggregated demand. The authors proposed a stochastic EMS to account for renewables variability. This results in increased imports from the grid and the use of a local co-generation system, which translates into $15 \%$ higher costs over a nonstochastic EMS. This study shows that control systems have an influence on the economic performance of distributed energy generation for industrial processes. It should be noted that the services provided by the co-generation system could also be provided with renewable or storage technologies.

We identified four studies with demand-endogenous approaches. (8) Pamparana et al., (2017b) present the design of an on-grid combined PV and battery energy storage system to supply electricity for milling. The authors use this system for a semi-autogenous grinding mill and implement demand-side management (DSM) based on the classification of rocks by hardness. This approach of this study is single-vector and single-operation. The authors showed that PV can be more cost-effective when DSM is adopted. (9) In a later study, Pamparana et al., (2019a, 2019b) further analyze this DSM alternative by soft-coupling the energy system design model with a 
geometallurgical model of a mine. The authors analyze the effect of variability and uncertainty of rock hardness. They also propose a scenario where the mineral is classified into hard and soft stockpiles to illustrate a realistic implementation of this DSM alternative and they report cost reductions.

The previous example is one of many possibilities for shifting loads in mining for energy system flexibility. However, to the best of our knowledge, a comprehensive inventory of flexibility alternatives within copper production processes is still missing in the literature. We foresee further flexibility alternatives in the production of oxygen for smelting, which has a relevant electricity demand (Coursol and Mackey, 2010) and can be stored in tanks, and in the systems for water desalination and pumping, among others. All of these alternatives require a proper economic analysis that compares the cost of their implementation to the value of the flexibility they could provide to power systems. In power grids, the structure of the market would determine the ways the different participants of the system can benefit from the implementation of flexibility alternatives.

(10) Cruz-Robles et al. (2018) discuss the use of concentrated solar heat in copper smelting. The authors propose a central tower solar-thermal plant to supply the heat needs of this operation. They also consider modifying the energy demand of the process by changing the energy contributions from fossil fuels, pre-heating, and oxygen injection. They argue that the smelting operation could be carried out without direct use of fossil fuels and using only pre-heating and oxygen supply. This could allow for complete electrification. They do not size or design any specific system. Still, this approach would be demand-endogenous, single-vector, and single-operation. An integrated concept for heat and electricity supply using concentrated solar technologies is still to be modeled and analyzed, as well as its combination with other RE technologies. The fact that some smelters already have turbines to generate electricity using recovered heat could foster the adoption of the concentrated solar power (CSP). This, since part of the equipment required for a CSP plant, the turbines, is already familiar to the operation. In addition, the use of microwave or electric arc furnaces could be considered.

(11) In the last study considering modifications in the energy demand, Díaz-Ferrán et al. (2018) present an application of solar-thermal technologies. They propose using concentrated solar heat to produce gas from the waste tires of large mining trucks via pyrolysis. They evaluate the GWP of this alternative and compare it to pulverizing the tires or performing pyrolysis with conventional energy. Considering waste management as part of the operations involved in copper production, this study can be classified as demand-endogenous (since different configurations for the process, which would impact its energy demand, are assessed), non-exchangeable multi-vector (considers electricity and heat), and single-operation. This study does not size components of an energy supply system but compares the environmental performance of different technologies.

We observe a completely different approach in the scientific trend aiming at directly extract copper using solar heat and alternative chemistry, emerging as a third alternative to pyro- and hydrometallurgical methods. Experimental concepts have been proposed for copper sulfides (Sturzenegger et al., 2006) and oxides (L'vov, 2000; Murray et al., 1995).

We observe interesting results in the ongoing studies that suggest there is space for smarter integration of renewables in copper production. Barriers to do this, however, exist. Current models are not able to capture the complexity of energy demand in copper production. This is required to assess distributed multi-vector energy systems and energy demand flexibility in the copper industry. We expect that multi-vector systems and demand flexibility would allow cheaper designs. The modeling of the energy demand for water supply is untouched in the design of RE systems for copper supply. We expect this factor to be even more relevant in the future, as seawater use is 
increasing (as explained in section 3.1.3) and water reservoirs can be used for energy storage. In the modeling of energy technologies for copper production, there are mature technologies that still need to be included (e.g. heat pumps, electric heat, and hydrogen fuel cells). Analysis of these could also enable cheaper designs. In section 4, we elaborate on the recommendations for the design of RE systems for copper production, based on the analysis presented in this section and the learnings from other fields of application that we present in section 3.3.

\subsection{Studies on designing renewable energy systems in general}

In this section, we explore the scientific advances in designing energy systems for other distributed systems (section 3.3.1), national or regional grids (section 3.3.2), and the inclusion of environmental issues (section 3.3.3). We do this with the aim of identifying opportunities and drawing lessons that assist in designing cleaner energy systems for copper production.

\subsubsection{Distributed renewable energy systems}

Our examination of the literature on distributed renewable energy systems, with a focus on industrial applications, revealed two main approaches. Both methods combine different technologies to form exchangeable multi-vector systems, but they approach the design from different perspectives. On the one hand, we see approaches for distributed energy systems in the field of power systems optimization or system expansion models. This translates to cost optimization models (usually mixedinteger linear programming, MILP) to define the capacities of components in the energy system (energy generation, transport, and storage technologies) and its operation (energy flows in time). On the other hand, we see approaches for locally integrated energy sectors, in the field of process integration. These extend models intended to reduce the overall heat demand of a group of processes by recovering excess heat. In more general terms, as defined by Klemeš and Kravanja (2013), a family of methodologies for combining several parts of processes [...] for reducing the consumption of resources or harmful emissions. Therefore, these latter models would require a demand representation for the full process with a single-operation resolution (see Figure 7).

About distributed energy systems optimization, Mancarella (2014) reviewed the design and analysis of energy systems that incorporate different forms of energy (multi-vector or multi-energy systems), with a focus on distributed systems (distributed multi-generation). The author highlights that multi-vector systems improve the environmental and economic performance, as compared to supply systems designed for each vector (e.g. electricity, heat, or fuels) independently. This effect is more relevant in distributed systems. The components of distributed systems are often smaller, and with only a few units, the outage of one component can threaten reliability. Smaller scales also stress the effects that non-linear efficiencies could have on the optimal system configuration. With distributed systems confined in smaller geographic areas, the variations of renewable resources are harder to smooth out, as compared to larger systems. The local conditions of the energy market (e.g. fuel prices, on-grid electricity price, etc.) will have further influence on the optimal design and operation of distributed systems.

In terms of distributed multi-vector systems for industrial processes, Atabay (2017) developed a MILP model for designing exchangeable multi-vector energy systems for industrial processes at minimum cost. This model, called ficus, is open-source available online. It allows for dynamic prices, the import and export of energy from and to the grid, and considers transient behaviors and scale economies for different components. Ficus was originally applied to case studies for steel, aluminum, iron, carbon-based products, and car production processes. These case studies showed that the energy demand profiles of each industry strongly determine the cost-optimal capacities of the components in the energy system. This stresses the need for a thorough understanding of energy requirements for 
the industrial process one wants to analyze (how much energy, when, and for which use). Similarly, Scheubel et al. (2017) present a MILP model for designing a heat and electricity on-grid distributed supply system at minimum cost. The model considers combined heat and power, PV, wind, central heating, electricity, and heat storage technologies. The approach of the study is demand-exogenous, non-exchangeable multi-vector, and full-process with aggregated demand. Case studies with the model show considerable savings in the total energy costs as compared to current conventional energy systems (internal rates of return for the projects of up to 34\%, depending on the industry and its energy demand profiles). These results depend on the characteristics of the market. Such a model could similarly be useful in evaluating the effects of market conditions and public policies on the optimal amount of distributed renewable energy generation at industrial sites. In turn, these conclusions could support planning in the regional and national energy systems where these industries participate.

Buoro et al. (2013) present a multi-objective optimization model for designing distributed energy supply systems and apply it to a group of industrial processes. This model allows for analyzing tradeoffs between the costs and $\mathrm{CO}_{2}$ emissions of the energy system. The authors considered combined heat and power, solar heat, and a heat distribution network (as a binary option) to provide electricity and heat. Following our classification, this approach is demand-exogenous, non-exchangeable multivector, and full-process with aggregated demand. Wang et al., (2017) include the possibility of implementing energy demand schedules in industrial processes. They implement an optimization model that includes operational scheduling as a decision variable. Such approaches can be especially interesting when analyzing how energy markets should be designed (signals and incentives for the players) to aid in the balancing of systems through industrial energy demand flexibility. This study is demand-endogenous, non-exchangeable multi-vector (heat and electricity), and full-process with single operation resolution. The results suggest benefits for both the industrial and power grid operators from the implementation of such systems. MIND is one more model for the analysis of energy systems in industrial applications, focusing on the analysis of the management of energy demand dynamics or the implementation of efficiency measures (Karlsson, 2011). An application of this method to an iron foundry is presented by Thollander et al. (2009). The authors analyze the impacts of changing the smelting equipment on the total energy costs of the process, highlighting the suitability of energy system optimization models for assisting the design of industrial processes.

In terms of the second main approach, locally integrated energy sectors (or, more generally, process integration), Larsson et al. (2005) adapt the MIND model to analyze process integration for steel production. They quantify the effects of different modifications to the process operation and equipment on the energy demand of the process. This type of model requires detailed modeling of every operation in each process, to identify and assess energy recovery and energy efficiency measures. This type of model does not focus on identifying optimal mixes for energy generation and storage, which distinguishes it from optimization models for distributed energy systems. In spite of this, there are efforts to use process integration-based models to design RE systems (Mohammad Rozali et al., 2014). These techniques are more than 40 years old (Klemeš and Kravanja, 2013), but have been evolving continuously. Klemeš et al. (2018) argue that more recent developments (e.g. the entire field of total site heat integration (Liew et al., 2017)) should be considered to enhance the performance of processes.

A further degree of complexity is added when considering the very low future costs for PV electricity generation. We anticipate that it could happen that the configuration that minimizes energy demand may not be the same as the one that minimizes costs. Shifting load profiles to daylight could yield cheaper solutions, even when resulting in increased total energy consumption. 
There are several fully renewable island energy systems in the world (Jung and Villaran, 2017; Kirchhoff et al., 2016; Kuang et al., 2016). The operation of these systems is based on control systems that differ from the current techniques in power systems (Pinceti et al., 2017; Unamuno and Barrena, 2015), where conventional technologies dominate. The main difference is the use of more frequent real-time measurements to determine the amount of power to be delivered by each generation unit (dispatch). This is done so that despite the variability of the renewables, the electricity demand is always satisfied (Li et al., 2017; Nosratabadi et al., 2017). To smooth out this variability, complementary systems (like water supply) can be coordinated to increase the hosting capacity for renewables in the energy system (Morvaj et al., 2017; Neves et al., 2018; Yoldaş et al., 2017). The excess of electric energy is used to fulfill additional demands and/or is transformed into other energy vectors (e.g., heat). From this perspective, large industrial processes pose an attractive context for moving towards fully renewable energy systems ( $\mathrm{Li}$ et al., 2017). Since they are multi-vector energy systems, the variability of renewables can be smoothed-out by taking advantage of the synergies between the different individual industrial processes (Arlt et al., 2017; Fang et al., 2018; Schoonenberg and Farid, 2017). Consequently, going towards a fully renewable energy system for copper production raises the following question: how the individual operations should be scheduled to adapt the energy demand to the availability of renewable energy resources. This requires a rethink of copper production processes.

\subsubsection{Renewable energy systems for regional grids}

This section examines the design of renewable energy systems at the regional level (states, countries, or even continents) in order to draw relevant conclusions for designing a fully renewable energy supply for the copper industry. In recent years, many studies on the planning of large-scale energy grids have emerged. The majority focuses on integrating high shares of renewable technologies. Cebulla et al. (2018) analyzed 500 scenarios arising from almost 20 studies to derive the storage requirements for the U.S. and Europe for increasing shares of renewables. Beyond the explicit numbers, they underline that, when designing highly renewable systems, attention needs to be paid to the generation mix and the transmission system. When the penetration of renewables grows greater than $50 \%$ (of annual demand), storage technologies are needed, especially if the grid relies more on solar than on wind power. This is consistent with the findings from Zerrahn and Schill (2017), who reviewed 60 studies.

Continuing the analysis of the challenges in renewable systems planning, another recent review is provided by Haas et al. (2017). They systematize the planning approaches of about 90 journal publications and derive challenges and trends for large energy grids. The authors recommended acknowledging technological diversity (including efficiency-, lifetime-, and cost-curves) to understand better how technologies can complement each other; improve the spatial and temporal resolution to better capture the variability of renewables; represent the diverse services (beyond energy balancing) that are needed in the operation of power systems, such as reserve capacity; and include the different energy sectors, as these can support each other and may have flexibility readily available. Zerrahn and Schill (2017) also see sector-coupling (like multi-vector systems, but for large-scale systems) as particularly critical when reaching very high levels of renewables. In addition, they recommend capturing the full spectrum of flexibility options; besides energy storage and sector-coupling, this includes demand-side management and transmission reinforcement and expansion. The interaction of future regional energy systems with the industrial sector, particularly copper production, would be defined by the flexibility that the energy demand of the industry can provide. 
In terms of temporal resolution, the current standard for models is an hourly time-resolution, for renewable system design on a regional level (Brown et al., 2018). Coarser resolutions would underestimate the variability of renewable generation and risk under-sizing the storage capacity (Diaz et al., 2019). In more precise resolutions the resources are quite uncorrelated; in other words, their variability tends to cancel out, which is why a more refined time resolution does not add much value in large systems. This stands in contrast to planning the infrastructure for distributed renewable energy systems, where the area is smaller and the time resolution needs to be higher to achieve the same effect. For example, for wind turbines, turbines separated by around $10 \mathrm{~km}$ would require a time-resolution of about 5 minutes to exhibit an effect equivalent to that of those separated by 200 $\mathrm{km}$ with a time resolution of 1 hour (Ernst, 1999).

Another relevant issue in energy systems modeling is the consideration of uncertainty. One of the main sources of uncertainty is the future costs of technologies. To project these costs, learning curves are commonly used, as in Child et al. (2017). When using these curves, one should pay attention to the effects of cost increases in early commercialization, the phenomena of forgetting, and economic and socio-political factors (Yeh and Rubin, 2012). An additional source of uncertainty arises when the planned system has a reliance on fossil fuels, whose prices are extremely hard to predict. Fortunately, the relevance of this source of uncertainty will decrease for growing shares of renewables. Uncertainty in energy systems planning can be dealt with methods that differ in complexity. These range from scenario analysis to Monte Carlo simulation and other stochastic approaches. The selection of the adequate method depends on the nature of the source of uncertainty and the goals of the study (Haas et al., 2017).

In summary, three aspects relevant to the energy systems of copper production are identified. First, distributed generation is more exposed to the variability of the (local) resources and thus the value of flexibility, in any of the presented forms. Second, grid-connected mines have a bidirectional relationship with the power system: they can profit from the flexibility of the grid and offer demand flexibility to the grid. We expect that energy planning tools that consider this alternative will achieve cheaper solutions. Third, there are several approaches to deal with uncertainty when designing energy systems, which can be easily applied to copper production.

\subsubsection{Environmental impacts in energy systems modeling}

This section analyses the integration of environmental impact indicators into the design of energy systems. All the models listed for the design of copper production systems focus on costs, direct emission of $\mathrm{CO}_{2}$, and/or use of energy as a further objective to be minimized. In view of the significant impacts that energy supply has globally on human health, ecosystems and resource availability, future research should include environmental sustainability in the design of future copper production. Here we can learn from current studies in energy system analysis, which incorporate LCA-based indicators into the design of large-scale energy systems. For example, Pehl et al. (2017) show that pricing indirect $\mathrm{CO}_{2}$ emissions reduces the global electricity production from gas, hydropower, and bioenergy, and increases the shares of CSP, wind and nuclear energy. Rauner and Budzinski (2017) consider the whole LCA perspective by including the single-score ReCiPe indicator in the objective function. They show that environmentally sustainable systems drastically reduce fossil fuel-based power generation, with a shift towards high shares of wind and PV technologies. Research can present trade-offs such as those between costs and environmental impacts; it is up to stakeholders to decide what set of tradeoffs to accept.

Transferring LCA to the modeling of energy systems for copper production seems to be straightforward. For each technology, an LCA coefficient can simply be considered as model input. 
Limitations exist, however, from data availability and the granularity of life cycle inventories. In addition, assumptions about the technological progress of specific technologies in copper production (foreground database) and the evolution of the global energy supply are required as inputs for the LCAs (background database).

\section{Recommendations}

Drawing from the literature review and analysis from section 3, the following section aims at identifying specific recommendations for the modeling and design of future RE systems in copper production. Figure 8 provides an overview of the recommendations and the parts of a generic energy model that they cover (resources, energy conversion, flexibility, and/or demand).

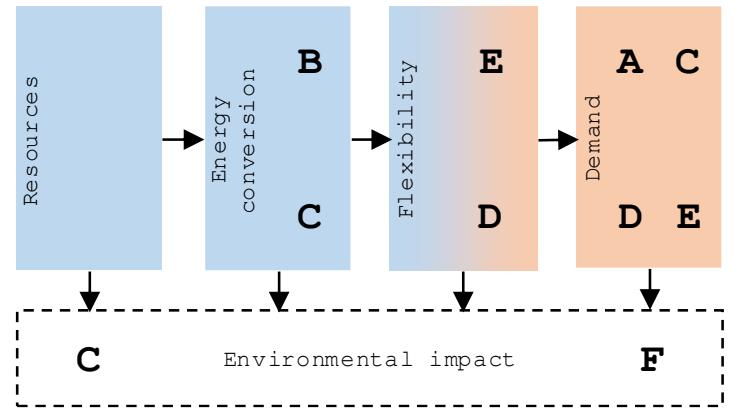

Figure 8: The recommendations and the component of a generic energy system model that they cover. Each letter represents a recommendation.

\subsection{Recommendation A: Improve energy demand models}

In section 3.2.2, we saw that the detail of the energy demand of copper mines in literature is poor, both for the operations within the production processes and in the characterization of the final forms of use. In the current paradigm, where dispatchable (mostly fossil) technologies are used, rough characterizations of energy requirements could suffice. In highly renewable systems, an improved understanding of the energy demand for copper production processes is crucial for accurate system design. This means to describe better when, where, in which form, and for which purpose the energy is needed. Each of these characteristics is explained below.

Description of when means having demand profiles in a high time-resolution. This includes all cycles involved in the production processes throughout the year (seasonality), as well as the constraints and flexibilities in their maintenances.

Representation of where the energy is demanded is relevant since the location of the different stages in the production process determines the energy demand for transport (distances) and heat (ambient temperatures). Also, altitude impacts pipeline transport and the performance of combustion processes (given the change in the partial pressure of oxygen). The location also determines the availability of renewable resources.

Description of the form in which and the purpose for which energy is demanded means the identification of heat (and temperature), electricity, fuels, and final use requirements. This allows for the identification of all potential solutions and the selection of the optimal technically feasible designs for integrated multi-vector systems.

\subsection{Recommendation B: Include multiple energy vectors in the analysis}

In addition to the overly simplified temporal and spatial treatment of energy demand, the literature also treats copper production poorly with regard to the energy vector. For example, it is common 
practice to limit the analysis to electricity or to identify the primary energy demand of fossil fuels as an aggregate of the demand for transport and heating processes (which take place at different temperatures). Basing the energy system design on such data biases the result towards solutions that simply replace the current energy vectors. Explicitly considering the different energy vectors (electricity, heat at different temperatures, and fuels, all convertible from one form to another) in the design of the energy supply system can enable solutions with lower environmental or economic costs, as explained in section 3.3.1. The point for sector coupling was further supported in section 3.3.2. From a modeling perspective, this can be addressed by (i) representing the energy demand by the final use or service it provides, (ii) integrating technologies for energy conversion, and (iii) defining a node for each form of energy.

A comprehensive range of technologies should be considered to find the optimal solution, as learned from the literature in section 3.3.2. We also observed (section 3.2.2) that there are mature energy conversion technologies that have not yet been considered in copper energy modeling (e.g. heat pumps or electric heat technologies). Broadening the range of technologies could reduce the total costs.

\subsection{Recommendation C: Integrate water management in the energy model}

As explained in section 3.1.3, water supply results in an energy issue for copper production in arid regions. In these regions, large quantities of energy are required for water transport (e.g. in Chile, 100 $\mathrm{km}$ long and $3000 \mathrm{~m}$ high (Haas et al., 2018)) and desalination. The energy demand for desalination is one and two orders of magnitude greater than those of groundwater and surface water extraction, respectively (IEA, 2016).

Sizing the water supply system within the energy system optimization model (endogenization) could enable more economical designs (as pointed out in section 3.3.1.). The option for water dams as energy storage technology can also be considered. Modelers should consider presenting this dual nature of the water supply system in a model for optimizing the energy system: (1) as a source of flexible energy demand for its transport and desalination and (2) as an energy storage alternative. In large scale systems, this idea has been addressed recently. For example, desalination has been considered in a study for the renewable energy transition of Europe (Manish et al., 2018). For local systems, having a detailed water infrastructure co-design is of even greater advantage, given the higher value of flexibility, as explained in section 3.3.2.

\subsection{Recommendation D: Explore demand-side management of current operations}

The fluctuations of renewable energy resources need to be balanced through a flexible system. This can be done by means of transmission expansion, storage, or demand flexibility, as illustrated for large systems in section 3.3.2. In highly renewable systems, more demand can be allotted in times when more RE is available. This can occur at different timescales and the profitability of implementing such measures would strongly depend on the characteristics of the local energy markets. In any case, from a systems perspective, considering this alternative provides further degrees of freedom to the optimization model, allowing it to find cheaper solutions, as explained in section 3.3.1.

Demand-side management is a very common flexibility option in general energy system design. However, in section 3.2.2 we observed that in the copper world the only example found was the management of rock feed to the mills. Undoubtedly, the copper sector has many other potential sources for operational flexibility, along different time horizons. In the following we list some of the examples we foresee: (1) The maintenance of plants could provide seasonal flexibility for highly solar energy systems by scheduling them in winter, thus reducing investment in long-term energy storage; 
(2) The smelter could provide short-term flexibility using its thermal inertia; (3) the oxygen production system at the smelter could provide flexibility by storing oxygen instead of energy; and (4) the upcoming truck-fleet electrification can implement smart charging strategies for demand-side management. However, the list of alternatives still needs to be completed and its value, possible compromises, and the impact on the optimal system design understood.

\subsection{Recommendation $E$ : Design future mines and processes to adapt to renewables availability and consider copper flexibility in energy planning}

In the past, when fossil fuels were the cheapest alternative, the energy was available on demand. As variable renewable technologies emerge as the cheapest alternative, we may benefit by adapting the production design to the availability of RE sources. Since the magnitude of many structural investment decisions in the mining industry makes them quasi-irreversible from an economic perspective, it is key that the options for matching the energy demand with renewable energy resources are considered in the early stages of project design. This means selecting and sizing equipment in consideration of the renewable energy variables. For example, when designing a new smelter, the selection of the smelting furnace will determine the form (electricity or fuels) and the amount of energy that will be required, as explained in section 3.1.3. In turn, this will affect the flexibility and costs of the overall energy system.

As seen in section 3.3.2, acting on the demand is not a new idea in large-scale systems. A direct example would be planning a power system with electric vehicles. The copper industry can also play a role in regional energy systems by providing additional flexibility to the system. We expect this role to be particularly relevant in countries where the energy demand of the industry is comparatively high, as in Chile (30\% of national electricity demand (Consejo Minero, 2019)). Consequently, we should consider the flexibility from the copper industry when planning energy systems for regions where this industry demands a relevant share of energy. In addition, the potential for energy flexibility should be considered when planning mining operations.

\subsection{Recommendation $F$ : Include environmental impacts in the assessment}

As the impacts of energy systems are not limited to greenhouse gases, a wider consideration of impacts is needed. Moreover, the environmental impacts of copper production go beyond its energy supply, as anticipated in section 1.3. Despite several studies having assessed individual environmental impacts of copper production, addressing them thoroughly when designing energy supply systems for copper has not been observed (as evidenced in section 3.2.2). Such an analysis should consider life cycle emissions so that tradeoffs can be identified. To this end, life cycle impact indicators can be integrated into energy systems optimization models as further objectives, as explained in section 3.3.3. Also, if modifications in the process-equipment are considered, its impacts should be considered. However, this kind of analysis is currently limited by data availability and its granularity (regions, technologies, and stages of the lifecycle).

\section{Conclusions}

We performed a comprehensive review of the design of renewable energy systems for copper production. To identify paths for further improvement, we explored the design of distributed renewable energy systems for other industrial processes and the design of regional systems.

Based on our review, we draw six recommendations for future research that would enable the design of more economical clean energy systems for copper production. The recommendations are: (a) improve energy demand models, (b) consider multiple energy vectors, (c) integrate water supply in energy system optimization, (d) assess energy flexibility of current production processes, (e) design 
future mines for flexible operation and consider copper flexibility in energy systems planning, and (f) include environmental impacts comprehensively in the design of energy systems for copper production.

The deployment of renewable energy systems, crucial to climate change mitigation, will demand more copper. Its production will continue to suffer from declining ore grades and the resulting increase in energy demand. Intensive use of renewable energy in copper production will help to mitigate the associated costs and environmental effects. This is happening naturally as renewables outperform conventional technologies on cost. We expect that designing systems based on our recommendations enables more cost-effective solutions and speeds up the transition to a $100 \%$ renewable energy supply.

\title{
Acknowledgments
}

Simón Moreno-Leiva thanks the support of the German Academic Exchange Service (DAAD) and the Chilean National Commission of Technology and Science [CONICYT PFCHA/DOCTORADO BECAS CHILE BILATERAL DAAD/2016 - 62160012]. This work was also supported by the Solar Energy Research Center SERC-Chile [CONICYT/FONDAP/15110019]; CONICYT [CONICYT/PIA Project AFB180004]; and the German Research Foundation [DFG-NO 805/11-1]. We further thank Isaac Alexander-Cook for language editing.

\author{
6. Nomenclature \\ COCHILCO Chilean Copper Commission (Comisión Chilena del Cobre) \\ CSP Concentrated Solar Power \\ DSM Demand-Side Management \\ EMS Energy Management System \\ GWP Global Warming Potential \\ LCA Life Cycle Assessment \\ MILP Mixed-Integer Linear Programming \\ PV Photovoltaics \\ RE Renewable Energy
}

\section{References}

Alvarado, S., Maldonado, P., Barrios, A., Jaques, I., 2002. Long term energy-related environmental issues of copper production. Energy 27, 183-196. https://doi.org/10.1016/S03605442(01)00067-6

Amusat, O., Shearing, P., Fraga, E.S., 2015. System design of renewable energy generation and storage alternatives for large scale continuous processes 2279-2284. https://doi.org/10.1016/B978-0-444-63576-1.50074-1

Amusat, O.O., Shearing, P.R., Fraga, E.S., 2017. On the design of complex energy systems: Accounting for renewables variability in systems sizing. Comput. Chem. Eng. 103, 103-115. https://doi.org/10.1016/j.compchemeng.2017.03.010

Amusat, O.O., Shearing, P.R., Fraga, E.S., 2016. Optimal integrated energy systems design 
incorporating variable renewable energy sources. Comput. Chem. Eng. 95, 21-37. https://doi.org/10.1016/j.compchemeng.2016.08.007

Arlt, M.-L., Ferreira Cardoso, G., Weng, D., 2017. Hydrogen storage applications in industrial microgrids, in: 2017 IEEE Green Energy and Smart Systems Conference (IGESSC). IEEE, pp. 1-6. https://doi.org/10.1109/IGESC.2017.8283465

Atabay, D., 2017. An open-source model for optimal design and operation of industrial energy systems. Energy 121, 803-821. https://doi.org/10.1016/j.energy.2017.01.030

Barrientos, J., López, J.D., Valencia, F., 2018. A novel stochastic-programming-based energy management system to promote self-consumption in industrial processes. Energies 11, 441. https://doi.org/10.3390/en11020441

Beylot, A., Villeneuve, J., 2017. Accounting for the environmental impacts of sulfidic tailings storage in the Life Cycle Assessment of copper production: A case study. J. Clean. Prod. 153, 139-145. https://doi.org/10.1016/j.jclepro.2017.03.129

Brantes, R., Cantallopts, J., 2018. Proyección del consumo de energía eléctrica en la minería del cobre 2017-2028. Santiago de Chile.

Brown, T.W., Bischof-Niemz, T., Blok, K., Breyer, C., Lund, H., Mathiesen, B. V., 2018. Response to 'Burden of proof: A comprehensive review of the feasibility of $100 \%$ renewable-electricity systems.' Renew. Sustain. Energy Rev. 92, 834-847. https://doi.org/10.1016/j.rser.2018.04.113

Buoro, D., Casisi, M., De Nardi, A., Pinamonti, P., Reini, M., 2013. Multicriteria optimization of a distributed energy supply system for an industrial area. Energy 58, 128-137. https://doi.org/10.1016/J.ENERGY.2012.12.003

Castilla, J.C., Nealler, E., 1978. Marine environmental impact due to mining activities of El Salvador copper mine, Chile. Mar. Pollut. Bull. 9, 67-70. https://doi.org/10.1016/0025-326X(78)904514

Castillo, P., Kouro, S., Rojas, C.A., Muller, N., 2015. Photovoltaic DC-DC converter for direct power interface to copper electrorefining process. IECON 2015 - 41st Annu. Conf. IEEE Ind. Electron. Soc. 4388-4393. https://doi.org/10.1109/IECON.2015.7392782

Castro-Molinare, J., Korre, A., Durucan, S., 2014. Sustainability Analysis of Copper Extraction and Processing using Life Cycle Analysis Methods: a Case Study in the North of Chile, 24th European Symposium on Computer Aided Process Engineering - ESCAPE 24 June 15-18, 2014, Budapest, Hungary. Elsevier. https://doi.org/10.1016/B978-0-444-63455-9.50102-1

Cebulla, F., Haas, J., Eichman, J., Nowak, W., Mancarella, P., 2018. How much electrical energy storage do we need? A synthesis for the U.S., Europe, and Germany. J. Clean. Prod. 181, 449459. https://doi.org/10.1016/j.jclepro.2018.01.144

Chen, T.T., Dutrizac, J.E., 1990. The mineralogy of copper electrorefining. JOM - J. Miner. Met. Mater. Soc. 42, 39-44.

Child, M., Breyer, C., Bogdanov, D., Fell, H.J., 2017. The role of storage technologies for the transition to a $100 \%$ renewable energy system in Ukraine. Energy Procedia 135, 410-423. https://doi.org/10.1016/j.egypro.2017.09.513

Choi, Y., Song, J., 2017. Review of photovoltaic and wind power systems utilized in the mining industry. Renew. Sustain. Energy Rev. 75, 1386-1391. https://doi.org/10.1016/j.rser.2016.11.127 
CNE (National Energy Commission Chile), 2019. Reporte Mensual Sector Energético. Santiago de Chile.

Cochilco, 2018. Información estadística sobre el consumo de energía en la minería del cobre al 2018. Santiago de Chile.

Cochilco, 2017a. Yearbook: Copper and the Mineral Statistics. Santiago de Chile.

Cochilco, 2017b. Informe de actualización del consumo energético de la minería del cobre al año 2016 [Update on the energy consumption of copper mining 2016]. Santiago de Chile.

Consejo Minero (Mining Council of Chile), 2019. Cifras actualizadas de la minería.

Consejo Minero (Mining Council of Chile), 2016. Minería en cifras Mayo 2016 (Mining in numbers May 2016). Santiago de Chile.

Coursol, P., Mackey, P.J., 2010. Energy consumption in copper sulphide smelting. Proc. Copp. 2010 649-668.

Coursol, P., Mackey, P.J., Kapusta, J.P.T., Valencia, N.C., 2015. Energy consumption in copper smelting: A new Asian horse in the race. J. Miner. Met. Mater. Soc. 67, 1066-1074. https://doi.org/10.1007/s11837-015-1380-1

Cruz-Robles, I., Vásques Vaamonde, A., Alonso, E., Pérez-Rábago, C., Estrada, C., 2018. Potential of solar central tower systems for thermal applications in the production chain of copper by pyrometallurgical route, in: AIP Conference Proceedings 2033. https://doi.org/10.1063/1.5067011

Díaz-Ferrán, G., Chudinzow, D., Kracht, W., Eltrop, L., 2018. Solar-powered pyrolysis of scrap rubber from mining truck end-of-life tires-A case study for the mining industry in the Atacama Desert, Chile, in: AIP Conference Proceedings. p. 20005. https://doi.org/10.1063/1.5067012

Díaz-Ferrán, G., Haas, J., Román, R., 2015. The integration between solar energy and mining in chile. Sol. World Congr. Proc. 8-12. https://doi.org/10.18086/swc.2015.10.40

Diaz, G., Inzunza, A., Moreno, R., 2019. The importance of time resolution, operational flexibility and risk aversion in quantifying the value of energy storage in long-term energy planning studies. Renew. Sustain. Energy Rev. 112, 797-812. https://doi.org/10.1016/j.rser.2019.06.002

Elshkaki, A., Graedel, T.E., Ciacci, L., Reck, B., 2016. Copper demand, supply, and associated energy use to 2050. Glob. Environ. Chang. 39, 305-315. https://doi.org/10.1016/j.gloenvcha.2016.06.006

Ernst, B., 1999. Analysis of wind power ancillary services characteristics with German 250-MW wind data. Golden. https://doi.org/10.2172/752651

Fang, X., Yang, Q., Dong, W., 2018. Fuzzy decision based energy dispatch in offshore industrial microgrid with desalination process and multi-type DGs. Energy 148, 744-755. https://doi.org/10.1016/J.ENERGY.2018.01.185

Fiscor, S., 2010. Major open-pit copper mines move underground. Eng. Min. J. 46-50. https://doi.org/ISSN 0095-8948

Haas, J., Cebulla, F., Cao, K.-K., Nowak, W., Palma-Behnke, R., Rahmann, C., Mancarella, P., 2017. Challenges and trends of energy storage expansion planning for flexibility provision in lowcarbon power systems - a review. Renew. Sustain. Energy Rev. 80, 603-619. https://doi.org/10.1016/j.rser.2017.05.201 
Haas, J., Palma-behnke, R., Valencia, F., Araya, P., Díaz-ferrán, G., Telsnig, T., Eltrop, L., Díaz, M., Püschel, S., Grandel, M., Román, R., Jiménez-estévez, G., 2018. Sunset or sunrise? Understanding the barriers and options for the massive deployment of solar technologies in Chile. Energy Policy 112, 399-414. https://doi.org/10.1016/j.enpol.2017.10.001

Harmsen, J.H.M., Roes, A.L., Patel, M.K., 2013. The impact of copper scarcity on the efficiency of 2050 global renewable energy scenarios. Energy 50, 62-73. https://doi.org/10.1016/j.energy.2012.12.006

Hertwich, E.G., Gibon, T., Bouman, E.A., Arvesen, A., Suh, S., Heath, G.A., Bergesen, J.D., Ramirez, A., Vega, M.I., Shi, L., Performed, L.S., 2015. Integrated life-cycle assessment of electricity-supply scenarios confirms global environmental benefit of low-carbon technologies. PNAS 112, 6277-6282. https://doi.org/10.1073/pnas.1312753111

IEA(International Energy Agency), 2016. Water Energy Nexus- Excerpt from the World Energy Outlook 2016. Iea. https://doi.org/10.1021/es903811p

Ihle, C.F., Kracht, W., 2018. The relevance of water recirculation in large scale mineral processing plants with a remote water supply. J. Clean. Prod. 177, 34-51. https://doi.org/10.1016/j.jclepro.2017.12.219

International Copper Association - Copper Alliance, 2014. Copper Recycling. New York.

International Copper Study Group (ICSG), 2018. Copper Market forecast 2018/2019 - Press release. Lisbon.

International Copper Study Group (ICSG), 2015. The world copper factbook 2015. Lisbon.

International Energy Agency IEA, 2018. World Energy Outlook 2018.

Jung, J., Villaran, M., 2017. Optimal planning and design of hybrid renewable energy systems for microgrids. Renew. Sustain. Energy Rev. 75, 180-191. https://doi.org/10.1016/j.rser.2016.10.061

Karlsson, M., 2011. The MIND method: A decision support for optimization of industrial energy systems - Principles and case studies. Appl. Energy 88, 577-589. https://doi.org/10.1016/J.APENERGY.2010.08.021

Kirchhoff, H., Kebir, N., Neumann, K., Heller, P.W., Strunz, K., 2016. Developing mutual success factors and their application to swarm electrification: microgrids with $100 \%$ renewable energies in the Global South and Germany. J. Clean. Prod. 128, 190-200. https://doi.org/10.1016/j.jclepro.2016.03.080

Kleijn, R., van der Voet, E., Kramer, G.J., van Oers, L., van der Giesen, C., 2011. Metal requirements of low-carbon power generation. Energy 36, 5640-5648. https://doi.org/10.1016/j.energy.2011.07.003

Klemeš, J.J., Kravanja, Z., 2013. Forty years of Heat Integration: Pinch Analysis (PA) and Mathematical Programming (MP). Curr. Opin. Chem. Eng. https://doi.org/10.1016/j.coche.2013.10.003

Klemeš, J.J., Varbanov, P.S., Walmsley, T.G., Jia, X., 2018. New directions in the implementation of Pinch Methodology (PM). Renew. Sustain. Energy Rev. 98, 439-468. https://doi.org/10.1016/j.rser.2018.09.030

Komatsu, 2009. Materials and specifications Komatsu 930E Electric Drive Truck. 
Kuang, Y., Zhang, Y., Zhou, B., Li, C., Cao, Y., Li, L., Zeng, L., 2016. A review of renewable energy utilization in islands. Renew. Sustain. Energy Rev. 59, 504-513. https://doi.org/10.1016/j.rser.2016.01.014

L'vov, B. V., 2000. Mechanism of carbothermal reduction of iron, cobalt, nickel and copper oxides. Thermochim. Acta 360, 109-120. https://doi.org/10.1016/S0040-6031(00)00540-2

Larsson, M., Wang, C., Dahl, J., 2005. Development of a method for analysing energy, environmental and economic efficiency for an integrated steel plant. https://doi.org/10.1016/j.applthermaleng.2005.05.025

Lazard, 2018. Lazard's Levelized Cost of Energy Analysis - Version 12.

Li, H., Tesfaye Eseye, A., Zhang, J., Zheng, D., 2017. Optimal energy management for industrial microgrids with high-penetration renewables. Prot. Control Mod. Power Syst. 2. https://doi.org/10.1186/s41601-017-0040-6

Liew, P.Y., Theo, W.L., Wan Alwi, S.R., Lim, J.S., Abdul Manan, Z., Klemeš, J.J., Varbanov, P.S., 2017. Total site heat integration planning and design for industrial, urban and renewable systems. Renew. Sustain. Energy Rev. 68, 964-985. https://doi.org/10.1016/j.rser.2016.05.086

Mancarella, P., 2014. MES (multi-energy systems): An overview of concepts and evaluation models. Energy 65, 1-17. https://doi.org/10.1016/j.energy.2013.10.041

Manish, R., Bogdanov, D., Aghahosseini, A., Gulagi, A., Oyewo, S.A., Child, M., Caldera, U., Sadovskaia, K., Farfan, J., Barbosa, L.S., Fasihi, M., Khalili, S., Hans-Josef, F., Breyer, C., 2018. Global Energy System based on 100\% Renewable Energy - Energy Transition in Europe Across Power, Heat, Transport and Desalination Sectors. Study by LUT University and Energy Watch Group, Lappeenranta University of Technology Research Reports. Lappeenranta.

Martínez, E., Sanz, F., Pellegrini, S., Jiménez, E., Blanco, J., 2009. Life-cycle assessment of a 2-MW rated power wind turbine: CML method. Int. J. Life Cycle Assess. 14, 52-63. https://doi.org/10.1007/s11367-008-0033-9

Memary, R., Giurco, D., Mudd, G., Mason, L., 2012. Life cycle assessment: A time-series analysis of copper. J. Clean. Prod. 33, 97-108. https://doi.org/10.1016/j.jclepro.2012.04.025

Mohammad Rozali, N.E., Abdul Manan, Z., Hassan, M.Y., 2014. Optimal sizing of hybrid power systems using power pinch analysis. J. Clean. Prod. 71, 158-167. https://doi.org/10.1016/J.JCLEPRO.2013.12.028

Moreno-Leiva, S., Díaz-Ferrán, G., Haas, J., Telsnig, T., Díaz-Alvarado, F., Palma-Behnke, R., Kracht, W., Román, R., Chudinzow, D., Eltrop, L., 2017. Towards solar power supply for copper production in Chile: Assessment of global warming potential using a life-cycle approach. J. Clean. Prod. 164, 242-249. https://doi.org/10.1016/j.jclepro.2017.06.038

Morvaj, B., Evins, R., Carmeliet, J., 2017. Comparison of individual and microgrid approaches for a distributed multi energy system with different renewable shares in the grid electricity supply. Energy Procedia 122, 349-354. https://doi.org/10.1016/j.egypro.2017.07.336

Murray, J.P., Steinfeld, A., Fletcher, E.A., 1995. Metals, nitrides, and carbides via solar carbothermal reduction of metal oxides. Energy 20, 695-704. https://doi.org/10.1016/0360-5442(95)00032$\mathrm{C}$

Neves, D., Pina, A., Silva, C.A., 2018. Assessment of the potential use of demand response in DHW systems on isolated microgrids. Renew. Energy 115, 989-998. 
https://doi.org/10.1016/J.RENENE.2017.09.027

Nordelöf, A., Messagie, M., Tillman, A.M., Ljunggren Söderman, M., Van Mierlo, J., 2014. Environmental impacts of hybrid, plug-in hybrid, and battery electric vehicles - what can we learn from life cycle assessment? Int. J. Life Cycle Assess. 19, 1866-1890. https://doi.org/10.1007/s11367-014-0788-0

Norgate, T., Jahanshahi, S., 2010. Low grade ores - Smelt, leach or concentrate? Miner. Eng. 23, 6573. https://doi.org/10.1016/J.MINENG.2009.10.002

Norgate, T.E., Jahanshahi, S., Rankin, W.J., 2007. Assessing the environmental impact of metal $\begin{array}{lllll}\text { production } & \text { processes. } & \text { J. } & \text { Clean. } & \text { Prod. }\end{array}$ https://doi.org/10.1016/j.jclepro.2006.06.018

Northey, S.A., Mudd, G.M., Werner, T.T., Jowitt, S.M., Haque, N., Yellishetty, M., Weng, Z., 2017. The exposure of global base metal resources to water criticality, scarcity and climate change. Glob. Environ. Chang. 44, 109-124. https://doi.org/10.1016/j.gloenvcha.2017.04.004

Nosratabadi, S.M., Hooshmand, R.-A., Gholipour, E., 2017. A comprehensive review on microgrid and virtual power plant concepts employed for distributed energy resources scheduling in power systems. Renew. Sustain. Energy Rev. 67, 341-363. https://doi.org/10.1016/j.rser.2016.09.025

Pamparana, G., Kracht, W., Haas, J., Díaz-Ferrán, G., Palma-Behnke, R., Román, R., 2017. Integrating photovoltaic solar energy and a battery energy storage system to operate a semiautogenous grinding mill. J. Clean. Prod. 165, 273-280. https://doi.org/10.1016/j.jclepro.2017.07.110

Pamparana, G., Kracht, W., Haas, J., Ortiz, J.M., Nowak, W., Palma-Behnke, R., 2019a. Studying the integration of solar energy into the operation of a semi-autogenous grinding mill. Part II: Effect of ore hardness variability, geometallurgical modeling and demand side management. Miner. Eng. 137, 53-67. https://doi.org/10.1016/j.mineng.2019.03.017

Pamparana, G., Kracht, W., Haas, J., Ortiz, J.M., Nowak, W., Palma-Behnke, R., 2019b. Studying the integration of solar energy into the operation of a semi-autogenous grinding mill. Part I: Framework, model development and effect of solar irradiance forecasting. Miner. Eng. 137, 6877. https://doi.org/10.1016/j.mineng.2019.03.017

Pehl, M., Arvesen, A., Humpenöder, F., Popp, A., Hertwich, E.G., Luderer, G., 2017. Understanding future emissions from low-carbon power systems by integration of life-cycle assessment and integrated energy modelling. Nat. Energy 2, 939-945. https://doi.org/10.1038/s41560-0170032-9

Pinceti, P., Vanti, M., Giannettoni, M., 2017. Technical KPIs for microgrids. 2017 IEEE Int. Symp. Syst. Eng. ISSE 2017 - Proc. https://doi.org/10.1109/SysEng.2017.8088263

Ram, M., Bogdanov, D., Aghahosseini, A., Gualgi, A., Oyewo, S., Child, M., Caldera, U., Sadovskaia, K., Farfan, J., Barbosa, L., Fasihi, M., Kahlili, S., Dalheimer, B., Gruber, G., Traber, T., De Caluwe, F., Fell, H.-J., Breyer, C., 2019. Global energy system based on 100\% renewable energy - power sector. Lappeenranta, Berlin.

Ramos, O., Castro, S., Laskowski, J.S., 2013. Copper-molybdenum ores flotation in sea water: Floatability and frothability. Miner. Eng. 53, 108-112. https://doi.org/10.1016/j.mineng.2013.07.009

Rauner, S., Budzinski, M., 2017. Holistic energy system modeling combining multi- objective optimization and life cycle assessment Environmental impacts of high penetration renewable 
energy scenarios for Europe. Environ. Res. Lett. 12, 124005.

Scheubel, C., Zipperle, T., Tzscheutschler, P., 2017. Modeling of industrial-scale hybrid renewable energy systems (HRES) - The profitability of decentralized supply for industry. Renew. Energy 108, 52-63. https://doi.org/10.1016/j.renene.2017.02.038

Schipper, B.W., Lin, H.-C., Meloni, M.A., Wansleeben, K., Heijungs, R., van der Voet, E., 2018. Estimating global copper demand until 2100 with regression and stock dynamics. Resour. Conserv. Recycl. 132, 28-36. https://doi.org/10.1016/J.RESCONREC.2018.01.004

Schlesinger, M.E., King, M.J., Sole, K.C., Davenport, W.G., 2011. Overview, Fifth Edit. ed, Extractive Metallurgy of Copper. Elsevier. https://doi.org/10.1016/B978-0-08-0967899.10001-0

Schoonenberg, W.C.H., Farid, A.M., 2017. A dynamic model for the energy management of microgrid-enabled production systems. J. Clean. Prod. 164, 816-830. https://doi.org/10.1016/j.jclepro.2017.06.119

Servert, J.F., Cerrajero, E., Fuentealba, E.L., Greos, S., 2015. Feasibility of a CSP power plant in Chile under a PPA model, the role of soft financing and upfront grant. Energy Procedia 69, 1704-1710. https://doi.org/10.1016/j.egypro.2015.03.133

Sturzenegger, M., Winkel, L., Guesdon, C., 2006. Solar extraction of copper: on application of concentrated sunlight in extractive metallurgy. Miner. Process. Extr. Metall. 115, 31-40. https://doi.org/10.1179/174328506X91338

Teske, S., 2019. Achieving the Paris climate agreement goals: Global and regional 100\% renewable energy scenarios with non-energy GHG pathways for $+1.5^{\circ} \mathrm{C}$ and $+2^{\circ} \mathrm{C}$, Achieving the Paris Climate Agreement Goals: Global and Regional 100\% Renewable Energy Scenarios with NonEnergy GHG Pathways for $+1.5 \mathrm{C}$ and +2 C. Springer. https://doi.org/10.1007/978-3-030-058432

Thollander, P., Mardan, N., Karlsson, M., 2009. Optimization as investment decision support in a Swedish medium-sized iron foundry - A move beyond traditional energy auditing. Appl. Energy 86, 433-440. https://doi.org/10.1016/J.APENERGY.2008.08.012

Unamuno, E., Barrena, J.A., 2015. Hybrid ac/dc microgrids - Part II: Review and classification of control strategies. Renew. Sustain. Energy Rev. 52, 1123-1134. https://doi.org/10.1016/j.rser.2015.07.186

Vyhmeister, E., Aleixendri Muñoz, C., Bermúdez Miquel, J.M., Pina Moya, J., Fúnez Guerra, C., Rodríguez Mayor, L., Godoy-Faúndez, A., Higueras, P., Clemente-Jul, C., Valdés-González, H., Reyes-Bozo, L., 2017. A combined photovoltaic and novel renewable energy system: An optimized techno-economic analysis for mining industry applications. J. Clean. Prod. 149, 9991010. https://doi.org/10.1016/j.jclepro.2017.02.136

Wang, X., El-Farra, N.H., Palazoglu, A., 2017. Optimal scheduling of demand responsive industrial production with hybrid renewable energy systems. Renew. Energy 100, 53-64. https://doi.org/10.1016/j.renene.2016.05.051

Wei, D., Craig, I.K., 2009. Grinding mill circuits - A survey of control and economic concerns. Int. J. Miner. Process. 90, 56-66. https://doi.org/10.1016/j.minpro.2008.10.009

Wernet, G., Bauer, C., Steubing, B., Reinhard, J., Moreno-Ruiz, E., Weidema, B., 2016. The ecoinvent database version 3 (part I): overview and methodology. Int. J. Life Cycle Assess. 21, 1218-1230. https://doi.org/10.1007/s11367-016-1087-8 
Willuhn, M., 2019. Portuguese auction attracts world record bid of $€ 14.8 / \mathrm{MWh}$ for solar - pv magazine International [WWW Document]. PV Mag. Int. URL https://www.pvmagazine.com/2019/07/31/portuguese-auction-attracts-world-record-bid-of-e14-8-mwh-forsolar/ (accessed 10.10.19).

Yeh, S., Rubin, E.S., 2012. A review of uncertainties in technology experience curves. Energy Econ. 34, 762-771. https://doi.org/10.1016/j.eneco.2011.11.006

Yoldaş, Y., Önen, A., Muyeen, S.M., Vasilakos, A. V., Alan, İ., 2017. Enhancing smart grid with microgrids: Challenges and opportunities. Renew. Sustain. Energy Rev. 72, 205-214. https://doi.org/10.1016/J.RSER.2017.01.064

Zerrahn, A., Schill, W.P., 2017. Long-run power storage requirements for high shares of renewables: review and a new model. Renew. Sustain. Energy Rev. 79, 1518-1534. https://doi.org/10.1016/j.rser.2016.11.098 